\title{
La vida de María Magdalena en la Legenda Avrea de Iacobvs de Voragine y en Vides de Sants Roselloneses: un análisis comparativo*
}

\author{
Mª Carmen PUCHE LÓPEZ \\ Área de Filología Latina \\ Universidad de Alicante \\ carmen.puche@ua.es
}

\begin{abstract}
RESUMEN
En este artículo realizamos un estudio de la vida de Maria Magdalena en Vides de Sants Roselloneses, que es la traducción catalana más antigua que se conserva de la Legenda aurea de Jacobo de la Vorágine. El análisis comparativo desvela que la traducción mantiene sin apenas cambios el heterogéneo material narrativo de la uita y es, en general, fiel al texto latino, pero muestra una tendencia a la omisión de detalles narrativos que se hace muy marcada en ciertas secciones de la uita y que, en el caso del milagro de Marsella, comporta cambios y matices significativos para el relato.
\end{abstract}

Palabras clave: Hagiografía, María Magdalena, literatura comparada

\section{Mary Madeleine's life in Legenda Avrea by Iacobus de Voragine and Vides de Sants Roselloneses: a comparative analysis}

\begin{abstract}
In this article we make a study about Mary Madeleine's life as reflected in Vides de Sants Roselloneses, which is the oldest Catalan translation we have of Legenda aurea by Iacobus de Voragine. The comparative analysis points out that the translation keeps the heterogeneous narrative material without significative changes and it is, in general, faithful to the Latin text. However, it shows a tendence towards the omission of narrative details which becomes very remarkable in some sections of the Vita. This reduction involves subtle modifications and new nuances in relation to the "miracle of Marsella".
\end{abstract}

Keywords: Hagiography, Mary Madeleine, comparative literature. 


\section{Planteamiento y objetivos}

Como es bien sabido, la Legenda aurea de Jacobo de la Vorágine tuvo desde el momento de su aparición un impacto e influencia sin paragón y, eclipsando otras compilaciones como la Abbreviatio de gestis et miraculis sanctorum de Jean de Mailly o el Liber epilogorum in gestis sanctorum de Bartolomé de Trento, la obra se convirtió en una referencia fundamental traducida a numerosas lenguas vernáculas ${ }^{1}$.

En este trabajo vamos a centrar nuestra atención en la versión catalana más antigua que se conserva de la Legenda aurea, la habitualmente denominada Vides de Sants Roselloneses ${ }^{2}$, y vamos a realizar un estudio comparativo de la vida de Maria Magdalena en ambos textos ${ }^{3}$, prestando especial atención al llamado "milagro marsellés". Este episodio, que resulta particularmente interesante por sus conexiones con la narrativa antigua ${ }^{4}$ alcanza singular relevancia dentro del complejo y rico ciclo hagiográfico de la que es, sin duda, una las figuras más importantes de la santidad femenina ${ }^{5}$ : en la Legenda aurea, es el único de los milagros de la santa que ésta hace en vida, está narrado con mucho mayor más detalle que los restantes y, en conjunto, ocupa más de un tercio de la Vita de Jacobo de la Vorágine.

Nuestro análisis comparativo tiene dos objetivos:

1) Establecer el nivel de fidelidad de la versión catalana de la Vita en relación al texto latino de Vorágine.

2) Comprobar si el episodio del milagro recibe un tratamiento diferente por parte del traductor catalán en relación al resto de la Vita.

Para este trabajo seguimos la edición de Maggioni (1998) quien, como se sabe, defiende la existencia de dos redacciones de la Legenda aurea, la segunda de las cuales (LA2) es el fruto de la revisión a la que el propio autor sometió, en los últimos decenios de su vida, la primera versión (LA1) que había terminado de

\footnotetext{
${ }^{1}$ Sobre la difusión de la obra de Vorágine y su relación con otros legandarios pueden consultarse, por ejemplo, Reames 1985, especialmente 197 y ss.; Dunn-Lardaeu 1986; Maggioni 2006. Como señala A. Boureau (2004: XLVI), la influencia de la obra de Vorágine trasciende su propio contenido, ya que el esfuerzo de traducirla para hacerla accesible a un público que no leía latín significó un fuerte impulso y desarrollo de las lenguas vernáculas.

${ }^{2}$ Corominas la sitúa en el último cuarto del s. XIII, pero R. Cantavella, atendiendo al hecho de que el texto todavía menciona Vézelay como el lugar de culto de la santa, concreta más y considera que puede un poco anterior al 1280, antes de que la noticia del traslado en 1279 de las reliquias a Provenza por orden de Carlos de Anjou hubiera llegado a Rousillon (1996: 27 y ss.).

${ }^{3}$ Ya se han hecho estudios comparativos del texto latino y el catalán a propósito de otros santos, como el estudio de J. A. Ysern Lagarda (1990), centrado en la Vida de San Andrés.

${ }^{4}$ Esas conexiones, que ya han sido señaladas ( $c f$. G. Huet 1916; Walsh - Thompson 1986: 1; Archibald 1991: 56; Pinto-Mathieu 1997: 144) constituyen el punto de partida de nuestro estudio "Narrativa latina tardía en la Legenda aurea de Iacobus de Voragine: un episodio del De Sancta Maria Magdalena", en prensa.

${ }^{5}$ Sobre la figura de la santa, véanse, por ejemplo, Hansel 1937; Garth 1950; Saxer 1959; WalshThompson 1986; Pinto-Mathieu 1997 y 1998 o Jansen 2001.
} 
redactar en torno al decenio de 1260 (1998: XIII y ss.). De acuerdo a esta teoría, el objetivo de su edición es reconstruir el texto más cercano posible al que fue presumiblemente la última redacción de la obra (1998: XIV). Ahora bien, dado que la cronología propuesta por Cantavella para la traducción catalana de Vides es temprana (cf. supra n. 2), tomamos también en consideración las variantes de la primera versión (LA1), que se había ido difundiendo de forma paralela y uno de cuyos principales testimonios es el manuscrito V (Padova, Biblioteca Universitaria, ms. 1229; siglo XIII). Estas variantes son recogidas explícitamente por Maggioni en un aparato crítico paralelo para dar mejor cuenta de las diferencias entre LA1 y LA2 (1998: XIV) y a ellas aludiremos en las muy escasas ocasiones en que podrían ser significativas para valorar la originalidad del traductor catalán.

\section{Análisis comparativo}

\section{1. Características generales de la traducción}

El cotejo de la Vita de Sancta Maria Magdalena de Vorágine y el De senta Maria Magdalena de Vides (que designaremos VSR en adelante) nos permite hacer, en primer lugar, las siguientes observaciones de carácter general:

\section{1. 1. Composición de la uita}

Si Vorágine compone su Vita de Sancta Maria Magdalena a partir de un material narrativo muy heterogéneo tomado de diversas fuentes y ofrece la síntesis quizá más completa del rico ciclo hagiográfico de la santa ${ }^{6}$ el traductor catalán conserva sin cambios esta síntesis y la ordena de la misma manera:

1) Etimología

2) Historia del personaje, fruto del sincretismo de los tres personajes bíblicos: María de Magdala, María de Betania y la pecadora anónima que unge los pies de Jesús en casa de Simón el fariseo.

3) Huida de Judea y comienzo de la vida apostólica con su llegada a Marsella

4) Milagro de Marsella

5) Vida eremítica

6) Muerte junto a San Maximino

7) Translatio de sus reliquias desde Aix a Vézelay

8) Listado de milagros post mortem

VSR mantiene sin cambios, efectivamente, la abigarrada acumulación, fruto del método compilador de Vorágine ${ }^{7}$, de los diferentes elementos que componen

\footnotetext{
${ }^{6}$ El capítulo de Maria Magdalena de la Legenda aurea pertenece al grupo de los que derivan de varias fuentes, frente a los que derivan de una fuente única y a los que derivan de una fuente básica completada con glosas, comentarios o relatos de milagros (Boureau 1984: 86 y ss.). Una breve y clara revisión de las distintas partes que integran la leyenda tal como la recoge Vorágine y de los diferentes testimonios y uitae que conforman el ciclo hagiográfico magdaleniense puede verse en Mycoff 1989: 5 y ss.

${ }^{7}$ Cf. Boureau 1984: 208 y ss. y 1986; Geith 1993.
} 
la uita, y no altera tampoco la ordenación de bloques narrativos. Incluso la leyenda de que Maria Magdalena fue la prometida de Juan el Evangelista (caps. 182-187), insertada de manera un tanto forzada entre el milagro de la mujer encinta que sufrió un naufragio y el del ciego que recuperó la vista al visitar las reliquias de la santa en Vézelay, es conservada en el texto catalán, si bien omite la peyorativa valoración de la leyenda que incluye al final el dominico:

LA 182-187: Aiunt quidam Mariam Magdalenam sponsam fuisse Iohannis euangeliste, quam duxerat quando Christus de nuptiis ipsum uocauit. Ex hoc ipsa indignata, quod scilicet sponsum suum sibi abstulerat, abiit et omni uoluptati se dedit. [...] eum pre ceteris decorauit, quia a predicta delectatione eum remouit. Hec autem falsa et friuola repuntantur.

VSR: Disen alcuns que Senta Magdalena fo esposa de Sen Joan Evangelista, la qual avia presa per muler, adoncs quant Jhesuchrist lo-l apelà de les núpcies. On per aysò ela fo mot irada, per so cor li avia tolt lo seu espòs; per què ela pecà. [...] per aysò onrà tant Sent Joan davant tots los autres: car él lo partí dels delits de la santa dona.

Es también destacable que el traductor no añade juicios de valor propios ni tampoco elementos de transición, con lo que el salto entre un bloque narrativo y otro resulta tan abrupto como en el texto latino.

\section{1. 2. Referencias eruditas a fuentes y testimonios}

En tres ocasiones Vorágine hace referencia a una determinada fuente o autoridad que, bien avala el dato que él aporta, bien introduce variantes respecto de su propio relato. En estos casos el proceder del traductor catalán no es siempre el mismo.

Por un lado, conserva la oscura referencia a San Ambrosio como fuente de autoridad para, frente al testimonio de los Evangelios, atribuir a Marcela, la sirvienta de Marta, el saludo a Magdalena con la frase "Beatus uenter qui te portauit"”.

LA 31: Nam secundum Ambrosium illa fuit Martha et hec eius famula.

VSR: Segons que diu Sent Ambrosi, aquela fo Marta, e aquesta fo serventa d'ela.

Por otro lado, elimina en cambio la referencia a los testimonios de Hegesipo y de Josefo incluidos tras el relato de la muerte de María Magdalena (caps. 161-166):

LA 161-166: .... Iuxta ipsam se sepeliri precepit. Egesippus autem, uel secundum quosdam libros Iosephus, satis cum hystoria predicta concordat. Ait enim in quodam suo tractatu quod Maria Magdalena [...] iuxta altare in pace

\footnotetext{
${ }^{8}$ Sobre la versión que da Vorágine, totalmente diferente de la que ofrece el Evangelio, véase Boureau 2004: 1294, n. 10. Según el propio Boureau (ibidem n. 11), la cita de Ambrosio no está identificada. Sobre las fuentes patrísticas en la Legenda aurea, véase Fleith 1997.
} 
quieuit. Temporibus autem Karoli Magni...

VSR: e s manà sebelir costa ela cant seria mort. En lo temps de Carles Magnes...

Y omite, además, la mención de unos libros de Maximino en los que supuestamente se relata su encuentro con la santa ${ }^{9}$ :

LA 156: Conuersa dixit ad eum: "Accede huc, pater, propius nec fugias filiam tuam". Appropinquante autem illo, sicut in ipsius beati Maximini libris legitur, ita uultus domine ex continua et diuturna uisione angelorum radiabat ut facilius solis radios quam ipsius faciem intueri quis posset.

VSR: Ela dix: - Vine sà, sant pare, està prop de la tua fila!-. E ayxí con él la gardà en la cara, no o poc sostener, per la gran clartat de la sua vista, qui flameyava enayxí con sol.

Si atendemos a la tradición manuscrita del texto latino, cabría pensar, en un primer momento, que la omisión del pasaje de Hegesipo se debe a su modelo latino, ya que el pasaje está también omitido en el ms. V ( $c$ f. supra), pero ello no ocurre con los otros dos casos: la mención de los libros de Maximino sí consta en $\mathrm{V}$ y está omitida en VSR y, por otro lado, la leyenda del matrimonio de Magdalena y Juan el Evangelista, que no está tampoco en V, sí está recogida en el texto catalán.

Se trata, pues, de una omisión consciente del traductor, que considera superflua esta información, importante para el erudito y el compilador interesado en el contraste de fuentes o datos, pero irrelevante quizá para un público mucho más atento a la lógica interna de los acontecimientos relatados, a la cual estas referencias son ajenas.

\section{1. 3. Fidelidad y corrección de la traducción}

El traductor de VSR muestra un buen conocimiento de la lengua latina y ofrece generalmente una traducción correcta que, muchas veces, es estrictamente literal. Esta voluntad de recoger con fidelidad el texto latino se aprecia particularmente en la primera parte de la uita, donde se recoge la exégesis etimológica y la recopilación de fuentes bíblicas para identificar y caracterizar a Magdalena.

Por ejemplo:

LA 26: Hec est igitur illa Maria Magdalena cui dominus tam maxima beneficia contulit et tanta signa dilectionis ostendit.

VSR: Aquesta és, doncques, aquela Senta Maria Magdalena a la qual Déus donà tan grans benifeyts, e li mostrà mots seyals d'amor.

\footnotetext{
${ }^{9}$ La expresión no deja claro si se trata de libros consagrados a su figura o bien de libros escritos por él. En cualquier caso, como fuente de la narración del episodio sólo se aducen testimonios del ciclo hagiográfico de Magdalena y ninguno de Maximino (Boureau 2004: 1295, n. 25).
} 
Es destacable también que, cuando se repiten los términos latinos que corresponden a las interpretaciones del nombre de la santa, son recogidos coherentemente con el mismo término catalán. Así se puede observar en el pasaje siguiente en el que, además, se mantiene el juego etimológico latino:

\section{LA 10: uel Magdalena interpretatur turrita uel magnifica}

VSR: O Magdalena uol dir "garnida" o "gran"

LA 15: post conuersionem magnifica per gratie superabundantiam, quia ubi abundauit delictum, superabundauit et gratia.

VSR: Aprés la sua conversació fo gran, per gran habundància de gràcia, car là on habundaven falimens sobrehabundà gràcia

Incluso en unos pocos casos, y en contra de su tendencia a la simplificación y omisión de detalles narrativos ( $c f$. infra B.1.4), el traductor introduce una mínima amplificación a partir de una estructura sintética del texto latino en un esfuerzo por eliminar cualquier posible ambigüedad:

LA 24: Nam incole regionis illius propter uehementissimum solis ardorem unguentis et balneis utebantur.

VSR: per so cor les gens d'aquela region usen d'engens, per la calor del sol; $\boldsymbol{e} \cdot \mathbf{s}$ bayen sovèn.

LA 184: dominus ad penitentiam misericorditer ipsam conuertit. VSR: Jhesuchrist la convertí misericordiossament, e li fé fer penitència ${ }^{10}$

LA 92: Et ecce, non procul a naui quidam collis apparuit

VSR: E ayxí con éls estaven en aquestes paraules un mont los aparec a la mar

Junto a estos ejemplos, en los que se aprecia el interés de traductor por recoger escrupulosamente el significado de la expresión latina en cuestión, hay un pequeño número de pasajes en los que el traductor no parece haber comprendido correctamente el texto latino. Veamos cuáles $\operatorname{son}^{11}$ :

${ }^{10}$ También la especificación de los nombres de los padres de Magdalena:

LA 17: cuius pater Syrus, mater uero Eucharia nuncupata est

VSR: Lo seu pare avia nom Ciri, e la sua mare Eucària era apelada.

${ }^{11}$ Cabe incluir aquí lo que parecen ser descuidos más que omisiones voluntarias:

1) Hablando de la triple elección de Magdalena (penitencia, contemplación interior y gloria celestial), en la traducción catalana parte de la secuencia argumental está omitida y el significado de la explicación queda entonces oscuro e incompleto:

LA 5: De qua triplici parte intelligitur quod dixit dominus: "Maria optimam partem elegit, que non auferetur ab ea". Prima enim pars non auferetur ratione finis que est consecutio beatitudinis, secunda ratione continuationis quia contemplatio uie continuatur cum contemplatione patrie, tertia ratione sue eternitatis.

VSR: De la qual III part és entès so que Nostre Seyor dix: -Maria elec la nobla part, que no serà tolta d'ela. La primera part no's tolrà d'ela per raysó de fi, qu'és enseguiment de benaü- 
LA 18: Hec cum fratre suo Lazaro et sorore sua Martha Magdalum castrum, quod est secundo miliario a Genezareth, et Bethaniam, que est iuxta Iherusalem, et magnam Iherosolimorum partem possidebat.

VSR: E era Senta Maria heretera del castel Magdalo ab lo seu frare Sent Làer, e ab la sua sor Senta Marta. Es lo castel prop de Genezaret dos milers, e de Betània, que és costa Jherusalem; e gran partida de Jherusalem posseýa.

Mientras que en el texto latino, como indica el triple complemento directo (Magdalum castrum; Bethaniam; magnam Iherosolimorum partem), resulta evidente que Betania forma parte de las posesiones que Magdalena compartía con sus dos hermanos, en el texto catalán, en el que el tricolon queda desmontado en una sucesión de oraciones paratácticamente unidas, Betania es mencionada como un simple punto de referencia para indicar la situación de Magdalum y no como parte de los bienes compartidos por los tres hermanos ${ }^{12}$.

La voluptuosidad de Magdalena y su entrega a los placeres del cuerpo queda en el texto catalán transformada en una vaga mención de lo delicado de su cuerpo ${ }^{13}$ :

LA 20: Cum autem Magdalena deliciis corporis se totam exponeret

VSR: con Senta Maria Magdalena fos mot delicada de son cors

El verbo perpetior, que significa "sufrir, soportar pacientemente", es traducido, de forma inexacta, con un "avia perduda":

\section{LA 30: Martham sororem suam a fluxu sanguinis quem septem annis per- pessa fuerat \\ liberauit \\ VSR: sanà la sua sor Santa Marta de la corrensa de la sanc, que avia perdu- da VII ayns}

Según el texto latino, el abad del monasterio de Vézelay coparticipa con el duque de Borgoña en el envío a Aix de un monje con la misión de traer desde allí a Vézelay las reliquias de la santa. En el texto de Vides, en cambio, el nominativo

yransa; ni la segona part, per rasó de continüytat, car la contemplació de la via és continuad' ab la contemplació de la sua perdurabletat.

2) Hablando de los santos lugares a los que Pedro lleva a Peregrino, VSR omite el verbo principal ostendit y ello le lleva a convertir todos los acusativos, que en el texto latino eran complementos directos de ese verbo, en complementos de dirección:

LA 108: Petrus autem ipsum in Iherosolimam duxit et omnia loca in quibus Christus predicauit, miracula fecit, locum etiam in quo passus est et in quo celos ascendit eidem ostendit.

VSR: Enaprés Sen Pere menà lo príncep en Jhersusalem, e en tots los locs en los quals presicà

Jhesuchrist ni on fé miracles, e al loc on soferí passió, e là on se'n puyà al cel

${ }^{12}$ No obstante, la especificación del reparto que a continuación se incluye sí está correctamente traducida y no deja ya lugar a dudas:

LA 19: ...et Lazarus partem urbis Iherusalem et Martha Bethaniam possederunt

VSR: ...e Sent Làser ac la part de la ciutat de Jerusalem, e Senta Marta ac Betània

${ }^{13}$ Ya en su edición señala Coromines (1977: 78) que se trata de una "traducció errònia". 
es traducido como complemento de dirección, como si el abad no fuese agente sino destinatario de la acción de enviar ${ }^{14}$ :

LA 168: misit ipse et abbas ipsius monasterii monachum quendam cum decenti comitatu ad Aquensem ciuitatem

VSR: él tramès a l'abat del monestir un monge, per covinent compaya, en la ciutat d'Aychs.

Se trata, como vemos, de errores aislados, de detalle, dentro de una traducción que podemos calificar en general de correcta y ajustada, y es importante señalar que no hay discrepancias en la tradición textual que permitan explicar alguno de estos pequeños errores.

\section{1. 4. Omisión y reducción de detalles narrativos}

Esa literalidad que señalamos no es una constante a lo largo de toda la uita y el traductor muestra una significativa tendencia a la omisión de detalles narrativos que se produce a varios niveles: desde la supresión de términos o sintagmas aislados en el contexto de una frase en la que los demás elementos están recogidos con fidelidad, hasta la drástica simplificación y reducción de largos párrafos del texto latino a simples frases.

Veamos, en primer lugar, algunos ejemplos de supresión de términos aislados que, en unas ocasiones, son casi redundantes o se sobreentienden fácilmente $y$, en otras, aportan un matiz que se pierde en la traducción catalana:

LA 2: Per hec tria intelliguntur tres partes optime quas elegit, scilicet, pars penitentie, pars contemplationis interne et pars celestis glorie.

VSR: Per aquests noms són enteses les tres parts bones que ela alec a si, so és: part de penitència, e part de contemplació, e part de celestial glòria.

LA 20: Martha prudens partes sororis et fratris et suam strenue gubernabat VSR: Sent Marta governava les partides de sa sor e de son frare

LA 25: dominus illum de superba iustitia redarguit et mulieri omnia peccata dimisit

VSR: Jhesucrist lo’n reprès, e perdonà los pecats a Santa Magdalena

\section{LA 35: plures alii christiani}

VSR: ab mots d'autres

LA 43: Quare, cum tot diuitiis abundetis, sanctos dei fame et frigore mori permittitis?

VSR: Per qual rasó jaquits los sants de Déu morir per fam, con siats tan rics?

\footnotetext{
${ }^{14}$ Cabría añadir a esta breve lista de "errores" la traducción de LA 8 illuminabitur como fo il-luminada, pero en este caso hay variantes manuscritas (illuminabatur: $\beta C$ ) que no nos permiten confirmar que se trate de un error.
} 
LA 130: Interea beata Maria Magdalena superne contemplationis auida asperrimam heremum petiit

VSR: Senta Magdalena se n'anà en un hermitatye

LA 198: Magdalena nec ex toto dormienti nec ex toto uigilanti tamquam mulier formosa lugubres gerens oculos et duorum angelorum dextra leuaque sustentata presidio apparuit eique dixit.

VSR: Senta Maria Magdalena li aparec, ab dos àngels qui la sostenien, e dix-li.

LA 128: et a beato Maximino baptisma susceperunt. Tunc in ciuitate Marsilie omnia ydolorum templa destruentes Christi ecclesias construxerunt et beatum Lazarum in eiusdem ciuitatis episcopum unanimiter elegerunt.

VSR: e reseberen babtisme de Sant Maximí. E adoncs éls destruïren tots los temples de les ýdoles, e feren aquí motes gleses, e feren bisbe de la ciutat Sent Làser.

En otras ocasiones, ante expresiones latinas abstractas y grandilocuentes, organizadas en estructuras de dicola o tricola o bien de sustantivo abstracto + sustantivo en genitivo ${ }^{15}$, el traductor muestra una clara tendencia hacia la simplificación tanto sintáctica como semántica y opta por una expresión más simple y concreta.

Así, por ejemplo:

LA 37: assurgens uultu placido, facie serena, lingua diserta eos ab ydolorum cultura reuocabat et Christum constantissime predicabat

VSR: ela anà envés éls, e ab ses beles paraules ela·ls fasia partir de la eror de les ýdoles, e preïcava-los fortment Jhesuchrist.

LA 38: pre dulcedine eloquentie illius

VSR: de les sues paraules

LA 65: pro ipsis dominum exorauit ut sibi filium concedere dignaretur

VSR: Pregà Déus per éls que los donés fil

LA 78: puerulus palpitabat et mammillarum maternarum querens solatia lamentabiles dabat uagitus

VSR: E l'enfant palpava, ploran, les tetes de la sua mare

LA 131: In quo quidem loco nec aquarum fluenta nec arborum nec herbarum erant solatia ut ex hoc manifestaretur quod redemptor noster ipsam non terrenis refectionibus, sed tantum celestibus epulis disposuerat satiare.

\footnotetext{
${ }^{15}$ El latín de Vorágine, si bien no es particularmente recargado y es un ejemplo de sermo humilis, tiene un cierto nivel de artificiosidad y elaboración que se observa en algunas estructuras sintácticas de cierta complejidad o en su gusto por cerrar frases con cláusulas de cursus. Sobre los diversos estilos de los textos latinos medievales, véase Bourgain 2005: 393 y ss.
} 
VSR: En lo qual loc no avia ayga ni erbes ni aybres; per què fo manifest que Déus li donà a menyar.

LA 143: Accede propius et omnium que desiderat anima tua scire poteris ueritatem

VSR: Vine costa mi, e poyràs saber veritat d'aysò que desiges!

LA 180: femina quedam specie et habitu ueneranda

VSR: una femna honestament vestida

\section{LA 188: Vir quidam oculorum lumine priuatus}

VSR: Fo un baró que res no vesia

Finalmente, y yendo un paso más allá de estas reducciones que afectan a sintagmas o frases determinadas, en ciertos momentos de la uita el traductor omite de forma sistemática frases completas y, más que traducir, "resume" el latín, un tanto reiterativo de Vorágine, en expresiones mucho más concisas y simples, en un intento de imprimir mayor agilidad y sencillez a la narración.

La descripción del encuentro del eremita con Magdalena es particularmente representativa de este drástico reduccionismo, que contrasta fuertemente con la literalidad que hemos visto en otros casos. Así lo demuestran los siguientes pasajes:

-La contemplación, por parte del sacerdote, del descenso de los ángeles para llevarse al cielo a Magdalena:

LA 134-135: Sacerdos autem quidam solitariam uitam agere desideras ad duodecim stadia loco eidem uicinam sibi cellam locauit. Die igitur quadam dominus predicti sacerdotis oculos aperuit et corporeis oculis euidenter aspexit qualiter angeli ad predictum locum in quo beata Maria Magdalena morabatur descendebant et eam in ethera subleuabant et post hore spatium ad eundem locum cum diuinis laudibus reuocabant.

VSR: Fo un prevere qui estec en ermitatye prop d'ela XII stats; e vesec un dia en qual manera los àngels venien a Santa Magdalena, ni con la levaven en l'àer, ni co la'n tornaren, cantan, en son loc.

-Su intento, reiteradamente fallido, de encaminar sus pasos al lugar donde ha visto el portento:

LA 136-138: Volens autem sacerdos tam admirabilis uisionis ueritatem agnoscere creatori suo precibus se commendans ad predictum locum audaci deuotione properabat. Cumque ad unius iactum lapidis propinquaret, ceperunt eius crura resolui et timore ualido ipsius precordia medillitus anhelare. Cumque retro rediret, ambulandi usum crura cum pedibus simul prebebant, sed si uerso tramite ad predictum locum accedere conaretur totius eum languor corporis et hebetudo modis omnibus prohibebant.

VSR: E co'l preveyre volgés anar en aquel loc, quant fo prop del loc, no poc anar; per què se n'ac a tornar: 
-El sacerdote comprende que estaba siendo impedido por la divinidad:

LA 139: Intellexit igitur uir dei illud procul dubio celeste esse sacramentum, ad quod accedere humanum non poterat experimentum.

VSR: per què, conec que Déus no o volia que él i anés.

-Magdalena le explica cómo ha vivido durante treinta años gozando de la compañía de los ángeles y oculta a todo ser humano:

LA 147: Ego, inquit, sum illa que per triginta annorum spatium omnibus hominibus ignota permansi et sicut heri tibi cernere permissum st sic diebus singulis angelicis manibus inethera subleuata celestium agminum dulcissimam iubilationem septenis uicibus per singulos dies corporeis auribus audire promerui.

VSR: Eu són aquela, que he ayxi estat, per XXX ayns, ses que eu no yc vi nul hom sinó los àngels del meu Seyor, qui·m donen aquel gaug que tu veus.

Así pues, podríamos decir que, frente a la literalidad que, de manera general, caracteriza la traducción de la primera parte de la uita, en el relato del retiro eremítico el traductor cambia de método de trabajo: elimina gran cantidad de detalles y busca agilizar el ritmo narrativo recogiendo los datos imprescindibles del episodio y evitando la recreación prolija y detallada que hace Vorágine.

\section{1. 5. Transformación y simplificación de estructuras sintácticas}

En el texto catalán predominan las estructuras coordinantes y, en algunos casos, se simplifican estructuras latinas que presentan cierto nivel de complejidad sintáctica, al desplegar diversas subordinadas a partir de un solo verbo principal. En lo que respecta a las construcciones participiales, que son bastante frecuentes en el texto de Vorágine, quedan transformadas, bien en formas personales unidas mediante coordinación al que es verbo principal en la oración latina, bien en subordinadas (muchas veces, temporales). Veamos algunos ejemplos:

LA 169: Veniens igitur predictus monachus ad predictam ciuitatem, cum ipsam funditus a paganis destructam reperisset, casu quodam inuenit sepulchrum cuius sculptura marmorea demonstrabat quod corpus beate Marie Magdalene repositum intus erat.

VSR: E quant lo monge fo vengut a la dita ciutat, él la trobà destruýda per pagàs. E per aventur él atrobà lo sepulcre de Santa Magdalena, en lo qual era lo seu cors.

LA 76: Nauem igitur omnibus necessariis copiosissime onerantes et cetera que habebant in Marie Magdalene custodia relinquentes proficisci ceperunt VSR: Per què éls se meseren en una nau, ab mots de béns, e les autres causes que avien, éls gequiren en garda de Senta Magdalena

LA 77: Iamque unius diei et noctis cursu consummato cepit nimium mare 
intumescere, uentus flare ita ut omnes et maxime matrona grauida et debilis tam seua inundatione fluctuum quassati grauissimis angustiis urgerentur in tantum quod in ea subito dolor partus irruit et inter angustias uentris et pressuras temporis filium parturiens expirauit.

VSR: E quant agren anat un dia e una nuyt, la mar s'imflà per gran tempestat, ayxi que foren tots trebalats, en tant que la dona ac l'emfant que portava, e mantenent ela morí.

LA 107: Potens est enim dominus cui uult dona dare, data auferre, ablata restituere ac merorem in gaudium commutare.

VSR: car poderós és Déus qui dóna què pot tolre e, pux, que o reta; e pot la tua tristor en gaug retornar

LA 40: ut pro habenda prole ydolis immolaret

VSR: per so que sacrifiquessen a les ýdoles e que agessen enfantz

LA 179: Una autem femina, cum esset pregnans et se in mari periclitari conspiceret, Magdalenam in quantum poterat inclamabat uouens quod si meritis suis ab ipso naufragio euaderet et filium pareret, ipsum eius monasterio condonaret.

VSR: hon, co una femna fos preyn e vesés lo peril de la mar, ela reclamà Senta Magdalena, aytan aut co podia. E fé vot a Déu que si ela la deslirava del peril ni que posqués aver son fil, quant seria gran lo faria servidor del seu monestir.

LA 173: nullo modo inde reliquias mouere potuerunt donec ueniente abbate cum monachis cum processione honorifice sunt recepte.

VSR: no poc moure les relíquies: entrò l'abat, ab los monges, hi fo vengut honradament que $n$ portaren lo cors, Déus lausant.

LA 191-192: Quidam dum peccata sua in quadam cedula scripsisset, eam sub palla altaris beate Marie Magdalene posuit rogans eam ut sibi indulgentiam impetraret. Qui postmodum cedulam accipiens peccata sua de ipsa cedula omnino deleta inuenit.

VSR: Un home, dementre que escrivia los seus pecats en una carta, quant los ac escrits, él pausà l'escrit sots los draps de l'autar, e pregà Senta Magdalena que li enpetrés perdó dels seus pecats. E quan él pres la carta, él atrobà tots los pecats delits de la carta.

Por otro lado, algunas de las ya escasas estructuras de pasiva que hay en el texto latino son sustituidas por construcciones activas, incluso aunque ello represente en algún caso un cambio de verbo. Por ejemplo:

LA 34: ...beatus Maximinus, unus de LXXII domini discipulis, cui a beato Petro Maria Magdalena fuerat commendata

VSR: Sen Maximí, qui era un dels LXXII discípols del Seyor; al qual comanà Sent Pere Senta Maria Magdalena. 
LA 77: ita ut omnes et maxime matrona grauida et debilis tam seua inundatione fluctuum quassati grauissimis angustiis urgerentur

VSR: ayxi que foren tots trebalats

LA 175: qui dum in feretro a parentibus ploraretur

VSR: E ayxí co $l$ s parens lo portaven

LA 190: Statimque eius oculi sunt aperti

VSR: E mantenent él vesé la glesa

\section{2. El Milagro de Marsella}

En el marco de las observaciones expuestas en el apartado anterior, vamos a detenernos de manera particular en el relato del milagro marsellés que, como dijimos al principio, es una pieza narrativa extensa y de gran relevancia en la uita. En el relato se nos narra la llegada de Magdalena a Marsella, el comienzo de su actividad apostólica y su mediación para que, gracias a sus ruegos, la esposa del gobernador de la ciudad conciba un hijo. Después, cuando la mujer muere en la travesía a consecuencia del parto y es abandonada en la costa junto con el recién nacido, obra el milagro de alimentar al niño durante dos años hasta el regreso del padre y, finalmente, le devuelve la vida también a su madre. De alguna manera, con su actuación en este milagro, la santa completa sus otras facetas (amada de Cristo, predicadora y eremita) con una faceta de matrona y madre ${ }^{16}$, como le dirá la propia esposa del gobernador ("Magni meriti es, beata Maria Magdalena, et gloriosa, que in partu mei pressuris obstetricis implesti officium”). El episodio tiene, por tanto, gran significación en la caracterización de la santa y está relatado con gran detenimiento por Vorágine.

En su versión, el traductor catalán muestra la misma tendencia a la omisión de detalles narrativos que hemos señalado, pero no llega en modo alguno al nivel de escueto "resumen" en que transforma el episodio de la etapa eremítica de la santa. Por otro lado, es el único relato en el que, de manera excepcional en el conjunto de la uita, modifica detalles narrativos e introduce en la presentación de los acontecimientos pequeños cambios que imprimen nuevos matices al relato. Veamos cuáles son:

\section{2. 1. Reducción del papel de la Providencia y mayor protagonismo de Magdalena}

En la traducción catalana observamos una reducción del papel y del protagonismo de la Providencia, y eso se comprueba ya en el arranque mismo del relato y en la justificación de la llegada de Magdalena, Maximino y otros santos a la Provenza y, en concreto, a Marsella. En efecto, la explicación del éxodo forzado de que son víctimas todos los cristianos por parte de los infieles, que van buscan-

\footnotetext{
${ }^{16}$ Véase Jansen 2001: 294 y ss.
} 
do su muerte al hacerlos embarcarse en una nave sin timonel, no aparece en VSR. Igualmente, la llegada a Marsella, que en LA se produce por voluntad divina, se convierte en la versión catalana en una iniciativa activa y racional de los cristianos: son ellos los que se van, y lo hacen por miedo, y son ellos los que llegan a Marsella porque eligen ese destino, no por voluntad divina. Es una racionalización y eliminación del elemento sobrenatural y providencial, que despoja de esa aureola de "elegidos de Dios" al grupo que huye, que ya no son héroes protegidos por la Providencia, sino mortales asustados que buscan salvarse.

LA 35: omnes hii insimul et plures alii christiani naui ab infidelibus impositi et pelago sine aliquo gubernatore expositi ut omnes scilicet submergerentur diuino tandem nutu Marsiliam aduenerunt.

VSR: tots ensems, ab mots d'autres, per paor se'n vengren a Marsela

Cuando el gobernador pregunta a Magdalena por la verdad de la fe que predica, ella invoca la autoridad de su maestro, Pedro. En VSR, la autoridad de Pedro como cabeza de la Iglesia de Roma es menos explícita:

LA 61: Equidem illam defendere presto sum, utpote quotidianis miraculis et predicatione magistri mei Petri qui Rome presidet roboratam

VSR: Eu són aparelada de defendre la mia fe ab miracles, e ab la preÿcacion del masestra nostra qui és a Roma

Más adelante, cuando el gobernador y su esposa piden a Magdalena que ruegue a Dios para que les conceda un hijo, en la traducción catalana se insiste más en la idea de que es ella, más que la propia divinidad, la que consigue que la esposa del gobernador quede encinta:

LA 65: dictis tuis per omnia obtemperare parati sumus, si a deo que predicas nobis filium impetrabis

VSR: nós èm aparelats d'obesir als teus dits, si tu'ns acabas que nós ayam fil, ab lo teu Déus

LA 66: Cuius preces dominus exaudiuit et matrona illa concepit VSR: Per què la dona concebé

En la plegaria-imprecación que dirige Peregrino a Magdalena cuando abandona a su esposa y a su hijo (mucho más breve en VSR), se omiten diversas menciones de la intervención divina en el milagro de la concepción:

LA 94-101: O Maria Magdalena, cur ad perditionis et miserie mee cumulum Marsilie partibus applicuisti? Cur infelix admonitione tua hoc iter arripui? Petistine dominum ut mulier mea hac de causa conciperet, ut periret? Ecce enim concepit et pariendo mortem subiit; conceptumque est natum ut pereat, cum non sit qui enutriat. Ecce quod prece tua obtinui! Tibi cui mea omnia 
commendaui deoque tuo commendo: si potens est, memor sit anime matris et prece tua misereatur ne pereat natus."

VSR: - "O Magdalena, ¿per qual raysó est tu venguda a Macella, a la mia perdició? Per la tua amonició són eu en aquest peril, e la mia muler és mort ab son fil. Vè-la't ayxí: a tu la coman ayxí co mi; e comane les autres causes. Ayes mercè d'ela, per so que no peresca l'emfant nat."

Igualmente, en el momento de la milagrosa salvación del recién nacido y en el ruego de Peregrino para que devuelva a la vida a su esposa, VSR elimina el prece tua de Vorágine, con lo que parece atribuir enteramente a Magdalena la capacidad de otorgar el esperado desenlace:

LA 117: O beata Maria Magdalena, quam felix essem, quam mihi cuncta prospera aduenissent si mulier respiraret et mecum repatriare ualeret! Scio equidem, scio et procul dubio credo quod tu, qui puerum dedisti et in hac rupe per biennium pauisti, poteris matrem prece tua pristine restituere sanitati. VSR: O Maria Magdalena, e com seria ben pres si la mia muler resucitava! Creu certament que tu, qui às noyrit l'enfant, pots resucitar ela si-t vols.

En la mención del viaje a Aix, donde Maximino será nombrado obispo, se silencia que es la divina Providencia la que los encamina allí, así como los milagros que hacen en Aix para convertir a todo el pueblo a la fe cristiana:

LA 129: Tandem diuino nutu ad Aquensem ciuitatem uenerunt et populum illum ad fidem Christi per multa miracula adduxerunt, ubi etiam beatus Maximinus in episcopum est ordinatus.

VSR: E aprés éls vengren en la ciutat d'Ayx, en la qual éls convertiren tot lo pòbol; e feren bisbe de la ciutat Sent Maximí.

\section{2. 2. Reducción del protagonismo de la esposa del gobernador}

Buena parte de las omisiones que lleva a cabo el traductor catalán tienen que ver con la actuación de la esposa del gobernador de Marsella, cuyo protagonismo se ve notoriamente mermado en relación al que tiene en el texto de Vorágine. Veamos los pasajes en concreto:

1. Las dos apariciones de Magdalena ante ella antes de aparecerse a los dos quedan en el texto catalán reducidas a una ${ }^{17}$, eliminando la gradatio ascendente que conforma la secuencia en el texto latino y que confiere mayor dramatismo a

\footnotetext{
${ }^{17}$ En la vida eremitica, también las tres llamadas del sacerdote quedan reducidas a una sola en el texto de

Vides:

LA 140-142: Inuocato igitur saluatoris nomine exclamauit: "Adiuro te per dominum ut si homo es uel aliqua rationalis creatura que in illa spelunca habitas, mihi respondeas et tui edisseras ueritatem". Cumque hoc tertio repetisset, beata Maria Magdalena ei respondit.

VSR: E, nomenat lo nom Déu, él dix: -Eu te conjur per Déus que si tu est home o autra rasonal criatura, en aquela balma, que $m$ respones, e que $m$ diges ueritat! Per què Senta Magdalena li respòs, dién.
} 
la última aparición de Magdalena enfurecida. En virtud de esa reducción, la aclaración de que ella siente miedo de contar a su esposo la aparición de Magdalena queda omitida:

LA 45-46: Ipsa autem uiro suo indicare timuit uisionem. Sequenti igitur nocte eidem similia dicens apparuit, sed adhuc uiro suo hoc indicare neglexit.

VSR: Les quals paraules no volc dir a so marit

2. En las amenazas de Magdalena se obvia por completo su figura, caracterizada en el texto latino como uipera coniuge tua. Además, la traducción catalana evita los ecos bíblicos y diluye en buena medida el tono apocalíptico que resuena en las coléricas palabras de la santa para designar la maldad del gobernador (tyranne, membrum patris tui Sathane, crucis Christi inimice), llamado en el texto catalán simplemente mal home y, después, home enemic:

LA 48-51: "Dormisne, tyranne, membrum patris tui Sathane, cum uipera coniuge tua que tibi indicare noluit uerba mea? Quiescisne, crucis Christi inimice, diuersis ciborum generibus uentris tui refecta ingluuie et sanctos dei fame et siti permittis perire? Iacesne in palatio pannis inuolutus sericis et illos desolatos et sine hospitio uides et preteris? Non sic, inique, non sic euades nec impune feres quod tantum eis benefacere distulisti."

VSR: "O mal home, e dorms? Per qual rasó, con tu sies sadol, no dónes a menyar als santsde Déu, ni per què los gecs perir per fam ni per set? Tu yaus bé en ton palau ab bos draps de seda, e éls, són senes osdal. Sàpies, home enemic, que no escaparàs ayxí, per so cor tu às tant perlongat que no'ls às bé feyt."

3. En el diálogo de los esposo cuando él le hace saber su intención de visitar a Pedro, se reduce especialmente la respuesta de ella y se omite su leal y firme voluntad de acompañarle fielmente en todo momento, que es latín es expresado en un tricolon reforzado por juego etimológico y similicadencias:

LA 69: Cui dixit uxor eius: "Quid est, domine, putasne sine me proficisci? Absit! Te enim recedente recedam, te ueniente ueniam, te quiescente quiescam."

VSR: Al qual dix la sua muler: - "Eu te prec, séyer, que no vayes senes mi"

4. Después, mientras que el texto latino insiste en el empeño de la mujer y en cómo con súplicas consigue finalmente su propósito, el texto catalán es mucho más escueto :

LA 74: Econtra illa instabat, femineum nec mutans femina morem et cum lacrimis pedibus eius prouoluta quod petebat tandem obtinuit.

VSR: Mes con ela no volgés romandre.

5. La explicación de cómo se siente ella en el momento en que se desata la tormenta y cómo se desencadena el parto, está omitida: 
LA 77: ut omnes et maxime matrona grauida et debilis tam seua inundatione fluctuum quassati grauissimis angustiis urgerentur in tantum quod in ea subito dolor partus irruit et inter angustias uentris et pressuras temporis filium parturiens expirauit.

VSR: ayxi que foren tots trebalats, en tant que la dona ac l'emfant que portava, e mantenent ela morí.

6. La única mención explícita que hay en el relato del afecto conyugal de Peregrino hacia su esposa, está omitida:

LA 121: Quo audito Peregrinus admirans ait: "Viuisne uxor mea dilecta?" Cui illa: "Viuo equidem..."

VSR: -

7. Cuando finalmente ella vuelve a la vida por obra divina, le dice a su marido que ha estado en los mismos lugares de Jerusalén que él y que, en ese viaje espiritual, Magdalena la ha acompañado. En VSR su explicación es mucho más breve y, además, se elimina la mención de que ella describe con todo detalle y sin ningún error los lugares visitados. Evidentemente, en el texto catalán se pierde el significativo paralelismo entre las palabras que ella pronunció cuando él le anuncia su intención de viajar (te recedente recedam, te ueniente ueniam, te quiescente quiescam) y las que ahora pronuncia sobre el resultado de ese viaje: de peregrinatione de qua et tu uenisti uenio:

LA 123-124: “...et nunc primo de peregrinatione de qua et tu uenisti uenio et sicut beatus Petrus te Iherosolimam duxit et omnia loca in quibus dominus passus est, mortuus et sepultus et alia plura loca ostendit, sic et ego una cum beata Maria Magdalena duce etcomite uobiscum fui et singula loca conspexi et conspecta memorie commendaui." Et incipiens omnia loca et miracula que uir uiderat adeo plene explicuit ut nec in articulo deuiaret.

VSR: Sàpies, tu, séyer meu, que eu són anada ab tu en tots aquels locs en los quals tu anest ab Sen Pere: e aquí m'acompayà Senta Maria Magdalena.

\section{2. 3. Actuación de Peregrino y de los marineros}

La narración de los acontecimientos que se suceden cuando muere la mujer tras el parto presenta pequeños cambios en el texto catalán que resultan particularmente novedosos, ya que son los únicos momentos de la uita en los que el traductor se permite introducir modificaciones, aunque mínimas, dentro del hilo argumental de la intriga.

VSR omite toda la reflexión que como narrador hace Vorágine sobre el recién nacido abocado a una muerte segura (cf. infra apartado 2.2.4) pero, en cambio, atribuye a Peregrino un sentimiento de ira y desesperación ausente en el texto latino, que resulta significativo ${ }^{18}$. Después, cuando Peregrino se encuentra

\footnotetext{
${ }^{18}$ Es curioso que el nombre de Peregrinus, que aparece en Vorágine a partir del momento del viaje, no aparece en ningún momento en la versión catalana y siempre se menciona al personaje con el
} 
con Pedro, se recoge otra vez el irat, en tanto que el texto latino recoge un moleste feras:

LA 79-84: Proh dolor! Et natus est infans uiuus et matricida effectus. Mori eum conuenit cum non sit qui uite tribuat alimentum. Quid faciet Peregrinus et cum uxorem mortuam uideat et puerulum uagientem querulis uocibus matris mammam appetentem? Lamentabatur plurimum et dicebat: "Heu heu miser, quid facies? Filium habere desiderasti et matrem cum filio perdidisti."

VSR: On con no agés què tetar, lo pare fo mot irat e trebalat per la mort de son fil e de la sua mare, dient: - Oy me! ¿Què faré, caytiu? Fil desiyaves e ara às perduda la mare e'l fil!

Cuando se avista el montículo, en el texto latino es Peregrino el que a duras penas convence a los marineros de que vayan hacia allí y al que se atribuye la idea de que es mejor enterrar que el cuerpo que arrojarlo al mar. En la traducción catalana, en cambio, no es Peregrino que reflexiona sobre lo que hay que hacer (credidit utilius) sino los propios marineros quienes, en pleno impulso y gesto de arrojar el cuerpo por la borda para conjurar los peligros de la tempestad, ven el montículo y optan por dejar el cuerpo en la costa. La narración resulta entonces más viva y dramática y refleja de manera mucho más eficaz el peligro de la situación y la incapacidad de Peregrino para controlarla, ya que el protagonismo de la acción no lo pierden en ningún momento los marineros y el "salvar por los pelos" el cuerpo de la mujer queda, con su intervención en estilo directo, más claramente de manifiesto:

LA 92: Et ecce, non procul a naui quidam collis apparuit, quo uiso utilius esse credidit corpus et puerulum illuc deferri quam marinis belluis ad deuorandum dari et uix a nautis prece et pretio extorsit ut illic applicarent.

VSR: E ayxí con éls estaven en aquestes paraules un mont los aperec a la mar, per què dixeren: -Milor és que nós los gitem en aquel mont, que si.ls gitàvem en la mar que ls menyassen los pexes-.

Por otro lado, al ser los marineros protagonistas de la acción de abandonar el cuerpo, en la versión catalana la plegaria de Peregrino resulta más forzada y pierde sentido, ya que él aparece de pronto junto a los marineros y toma la palabra. En el texto latino, en cambio, es él mismo quien deja y cubre los cuerpos y, lleno de dolor en ese momento, lanza su queja y su súplica a la santa. La aclaración de por qué no se puede enterrar el cuerpo, quizá necesaria para justificar que el esposo no cumpla con ese piadoso deber y para explicar que, posteriormente, el niño vague libremente por la orilla, no aparece en el texto catalán:

término príncep o con formas pronominales. Sólo en este pasaje se le llama pare, en el momento de la casi inminente muerte de su hijo, en tanto que en el texto latino nunca se utiliza el término pater o sinónimo para referirse a él. 
LA 93: Cumque illic pre duritia foueam non potuisset effodere, in secretiori parte collis clamide supposita corpus collocauit et puerulum mammis eius apponens cum lacrimis ait.

VSR: E ayxi éls pauseren ela e l'enfan, envolopats en un mantel, en aquel mont, e ayxí con lo príncep los posava aquí, él dix.

Cuando tiene lugar el viaje de retorno después de los dos años en Jerusalén, en el texto latino se especifica otra vez que Peregrino tiene que pagar a los marineros para que vayan hacia allá. En VSR, en cambio, no está la aclaración:

LA 110-111: Cumque nauigarent, domino disponente iuxta collem in quo corpus uxoris cum puerulo positum fuerat peruenerunt; qui prece et pretio eos ad ibi applicandum induxit.

VSR: E enayxí con él anava per la mar, Déus volent, éls vengren al mont on pausà la sua muler ab l'enfant.

\section{2. 4. Reducción de la voz del narrador}

La versión catalana elimina cualquier reflexión ajena al desarrollo mismo de los acontecimientos y que represente una valoración o enjuiciamiento del narrador sobre los hechos que describe. En el relato hay varias de estas omisiones:

1. La apostilla de Vorágine de que la capacidad persuasiva de Magdalena, cuya boca había besado los pies de Cristo, aventaja a la de los demás:

LA 39: nec mirum si os quod tam pia et tam pulchra pedibus saluatoris infixerat oscula ceteris amplius uerbi Dei spiraret odorem.

VSR: -

2. El lamento sobre la tragedia del pequeño que, con su nacimiento, ha provocado la muerte de su madre y está condenado también él a una muerte inevitable:

LA 79-84: Proh dolor! Et natus est infans uiuus et matricida effectus. Mori eum conuenit cum non sit qui uite tribuat alimentum. Quid faciet Peregrinus et cum uxorem mortuam uideat et puerulum uagientem querulis uocibus matris mammam appetentem? Lamentabatur plurimum et dicebat: "Heu heu miser, quid facies? Filium habere desiderasti et matrem cum filio perdidisti."

VSR: On con no agés què tetar, lo pare fo mot irat e trebalat per la mort de son fil e de la sua mare, dient: - Oy me! ¿Què faré, caytiu? Fil desiyaves e ara às perduda la mare e $\cdot$ l fil!

3. El razonamiento, explicado desde la perspectiva omnisciente del narrador, de que el niño se había salvado por obra de Magdalena y de que, como nunca había visto a nadie, se esconde bajo el manto de su madre cuando ve a su padre que, en su regreso de Jerusalén, pasa por el lugar donde había dejado a su esposa y a su hijo:

LA 112-116: Puerulus autem ibidem a beata Maria Magdalena incolumis conseruatus frequenter ad litus maris procedebat et ibidem, ut puerorum moris est, cum lapillis et glareis ludere solitus erat. Et cum applicuisset uidit 
puerulum more solito in litore maris cum lapillis ludentem et quidnam esset admirari non desinens de scapha exiliit. Quem uidens puerulus, cum nunquam tale quid uidisset, expauit et ad solita matris recurrens ubera occulte sub clamide latitabat. Peregrinus uero ut manifestius uideret illuc accessit et puerulum pulcherrimum matris ubera sugentem inuenit; et accipiens puerulum ait

VSR: E quan fo eixit de la nau, él atrobà l'emfant alegre, qui jugava ab peretes. E ayxi con el lo volc penre, l'enfant li fusc e anec-se metre sots lo mantel de la sua mare, e pres la teta a tetar, ayxí con solia. E quant assò vesé, él dix.

En el texto latino la explicación genera una especie de desdoblamiento, ya que se alude dos veces al hábito del niño de jugar en la playa (cum lapillis et glareis ludere solitus erat/more solito in litore maris cum lapillis ludentem) y dos veces también a su gesto de refugiarse en los pechos de su madre (ad solita matris recurrens ubera/matris ubera sugentem). En VSR, en cambio, el relato del descubrimiento del niño es más directo y gana en frescura e inmediatez: se omite la explicación inicial de la salvación milagrosa por obra de Magdalena, el sentimiento de admiración y sorpresa de Peregrino a medida que se acerca al pequeño, y también el sentimiento de miedo que éste experimenta al verle: se dice simplemente que Peregrino trata de coger al niño y que éste es el gesto que lo asusta $\mathrm{y}$, al mismo tiempo, se le atribuye al niño, quizá derivado de la repetición del verbo ludere, el adjetivo alegre, que no está en el texto latino.

\section{2. 5. Aspectos formales}

La prosa de VSR es una prosa sencilla y paratáctica, que busca ante todo la claridad y la concreción, como ya hemos señalado (cf. supra, apartado 2.1.4.). En el relato del milagro se confirma esta característica y, así por ejemplo, mientras que LA recurre a expresiones diferentes para designar la vuelta a la vida de la esposa de Peregrino (que constituye la actuación principal de la santa, junto con la milagrosa salvación del recién nacido), VSR utiliza en todos los casos el mismo verbo resucitar:

LA 117: O beata Maria Magdalena, quam felix essem, quam mihi cuncta prospera aduenissent si mulier respiraret et mecum repatriare ualeret! Scio equidem, scio et procul dubio credo quod tu, qui puerum dedisti et in hac rupe per biennium pauisti, poteris matrem prece tua pristine restituere sanitati.

VSR: O Maria Magdalena, e com seria ben pres si la mia muler resucitava! Creu certament que tu, qui às noyrit l'enfant, pots resucitar ela si-t vols.

LA 120: "Magni meriti es, beata Maria Magdalena, et gloriosa, que in partu mei pressuris obstetricis implesti officium et in omnibus necessitatibus ancille tue seruitium expleuisti.

VSR: De gran mèrit est, Santa Magdalena; beneseta sies tu que m'às donat so que volia, e m'às de mort resucitada.

O se utiliza el mismo verbo fer para traducir dos verbos latinos diferentes: 
LA 128: Tunc in ciuitate Marsilie omnia ydolorum templa destruentes Christi ecclesias construxerunt et beatum Lazarum in eiusdem ciuitatis episcopum unanimiter elegerunt.

VSR: E adoncs éls destruïren tots los temples de les ýdoles, e feren aquí motes gleses, e feren bisbe de la ciutat Sent Làser ${ }^{19}$.

Por otro lado, son también destacables algunas repeticiones casi formulares que generan una especie de paralelismo interno entre diferentes pasajes. Así, por ejemplo, en el caso de las amenazas de Magdalena, la repetición de un sàpies que marca un paralelismo entre las palabras que dirige al gobernador de Marsella y las que dirige a su esposa resulta significativa, ya que para obtener este paralelismo el texto catalán convierte en estilo directo lo que en latín es una simple subordinación:

LA 44: addiditque minas nisi marito suo persuaderet ut sanctorum inopiam subleuaret

VSR: “...Sàpies que mal te venrà, si a ton marit no ho dius que bé·ls fassa.”

LA 48-51: "Non sic, inique, non sic euades nec impune feres quod tantum eis benefacere distulisti."

VSR: "Sàpies, home enemic, que no escaparàs ayxí, per so cor tu às tant perlongat que no'ls às bé feyt."

LA 123: Viuo equidem et nunc primo de peregrinatione de qua et tu uenisti uenio

VSR: Sàpies, tu, séyer meu, que eu són anada ab tu en tots aquels locs en los quals tu anest ab Sen Pere

Algo similar ocurre un poco más adelante:

LA 61: Equidem illam defendere presto sum, utpote quotidianis miraculis et predicatione magistri mei Petri qui Rome presidet roboratam

VSR: Eu són aparelada de defendre la mia fe ab miracles, e ab la prë̈cacion del masestra nostra qui és a Roma

LA 65: dictis tuis per omnia obtemperare parati sumus

VSR: nós èm aparelats d'obesir als teus dits

Encontramos dos casos de juegos fónicos. En el primero, se recoge con una epanadiplosis lo que en el texto latino es una similicadencia:

LA 84: Heu heu miser, quid facies? Filium habere desiderasti et matrem cum filio perdidisti."

\footnotetext{
${ }^{19}$ Por el contrario, a propósito de la acción de lavar con lágrimas y secar con los cabellos los pies de Jesús, que es mencionada en varias ocasiones a lo largo de la uita (LA 23 y 32: lacrimis lauit, capillis tersit; LA 145: lacrimis rigauit et capillis tersit), el traductor elige términos diferentes en cada caso (ab les sues làgremes; ab los seus cabels; ab les làgremes, e ab los pèls; ab los uls, e ab los seus pèls)
} 
VSR: Oy me! ¿Què faré, caytiu? Fil desiyaves e ara às perduda la mare e·l fil!

En el segundo caso, se genera una similicadencia forzando un poco la traducción, ya que el traductor catalán interpreta el hoc iter arripui como són eu en aquest peril, además de reducir notablemente la queja de Peregrino:

LA 95: Cur infelix admonitione tua hoc iter arripui? Petistine dominum ut mulier mea hac de causa conciperet, ut periret? Ecce enim concepit et pariendo mortem subiit; conceptumque est natum ut pereat, cum non sit qui enutriat. Ecce quod prece tua obtinui! Tibi cui mea omnia commendaui deoque tuo commendo: si potens est, memor sit anime matris et prece tua misereatur ne pereat natus."

VSR: - "O Magdalena, ¿per qual raysó est tu venguda a Macella, a la mia perdició? Per la tua amonició són eu en aquest peril, e la mia muler és mort ab son fil. Vè-la't ayxí: a tu la coman ayxí co mi; e comane les autres causes. Ayes mercè d'ela, per so que no peresca l'emfant nat."

\section{Conclusiones}

El análisis que precede sobre la traducción catalana Vita de Sancta Maria Magdalena contenida en les Vides de Sants Roselloneses nos lleva a las siguientes conclusiones:

1. El traductor no elimina ni tampoco añade información sustancial al heterogéneo material narrativo de que se compone la uita y los matices originales y novedosos que detectamos en su traducción son de detalle.

2. La traducción es generalmente correcta y bastante fiel al texto latino, y son muy pocos los casos en que podemos hablar de claros "errores".

3. Muestra una marcada tendencia hacia la abreviación y omisión de detalles narrativos, desde la supresión de términos aislados hasta el drástico resumen de largos pasajes latinos. Esta tendencia a la simplificación se aprecia con mucha claridad en el relato del milagro de Marsella y en el del retiro eremítico de Magdalena, que son las dos piezas narrativas más extensas que contiene la uita, pero se hace particularmente acusada en la segunda, en que el encuentro del eremita con Magdalena y su actuación como mensajero ante Maximino quedan notablemente reducidos.

4. En el caso del milagro marsellés, la eliminación de detalles narrativos tiene consecuencias para el relato, ya que se reduce el papel de la Providencia en favor de un mayor protagonismo de la santa en el milagro, se resta relevancia al personaje de la esposa del gobernador y se suprimen todas las intervenciones de "narrador omnisciente" que hay en el texto latino, en la búsqueda de una mayor dramatización e inmediatez en la narración de los acontecimientos.

5. El relato del milagro es la única pieza narrativa de la uita en la que, además de las omisiones ya señaladas, encontramos también pequeñas modificacio- 
nes de ciertos detalles narrativos relativos a la actuación de los marineros cuando en la travesía muere la mujer a consecuencia del parto.

6. Desde el punto de vista formal, la traducción muestra un claro predominio de la parataxis y la coordinación, lo que comporta la sistemática simplificación de estructuras sintácticas latinas, particularmente las estructuras de participio. Es notoria también la preferencia por términos concretos, en lugar de las relativamente frecuentes construcciones latinas de sustantivo abstracto + genitivo. Algunas repeticiones generan ciertos paralelismos entre las intervenciones de los personajes y hay algunos ejemplos de sencillos juegos fónicos.

\section{Referencias bibliográficas}

BOUREAU, A. (1984): La Légende dorée. Le système narratif de Jacques de Voragine (+1298). Paris.

—idem (1986): "Les structures narratives de la Legenda aurea: de la variation au grand chant sacré", en Legenda aurea. Sept siècles de diffusion. Texte latin et branches vernaculaires. Actes du Colloque, B. Dunn-Lardeau (dir.), pp.5776. Montreal.

— idem (2004): "Introduction", en De Voragine, Jacques, La Légende dorée, texte traduit, présenté et annoté par A. Boureau et alii, pp. XV-LXVIII. Gallimard: Éditions Gallimard.

BOURGAIN, P. (2005): Le latin medieval. Turnhout: Brepols.

CANTAVella, R. (1990): "Medieval Catalan Mary Magdalen Narratives", en Saints and their Authors: Studies in Medieval Hispanic Hagiography in Honor of John K. Walsh, J. E. Conolly- A. Deyermond - B. Dutton (eds.), pp. 27-36. Madison. COROMINES, J. (1977): "Prefaci", en Vides de Sants Roselloneses, traducció catalana del s.. XIII de la Llegenda Daurada de Jacopo da Varazze, edició a càrrec de Charlotte $\mathrm{S}$. Maneikis Kniazzeh i Edward J. Neugaard. Barcelona: Fundació Salvador Vives Casajuana.

DUNN-LARDEAU, B.(dir.) (1986): Legenda aurea. Sept siècles de diffusion. Texte latin et branches vernaculaires. Actes du Colloque. Montreal.

FAILlON, E. M. (1865): Monuments inèdits sur l'apostolat de Sainte Marie Madeleine en Provence, 2 vols. Paris.

Fleith, B. (1997), "The Patristic sources of the Legenda aurea", en The reception of the Church Fathers in the West. From the Carolingians to the Maurists, Irena Backus (ed.), vol. I, pp. 231-287. Leiden-New York-Köln: E.J. Brill.

GAITH, K.-E. (1993), "Jacques de Voragine -auteur indépendant ou compilateur?", en Legenda aurea-La Légende dorée (XIIIe-XVe s.). Actes du Congrès international de Perpignan, Brenda Dunn-Lardeau (ed.), pp. 1731. Montreal: Éditions CERES Montreal.

GarTH, H. M. (1950): Saint Mary Magdalene in medieval literature. Baltimore. HANSEL, H. (1937): Die Maria-Magdalena-Legende. Eine QuellenUntersuchung. Greifswald. 
YSERn LAgARDA, J. A. (1990): “La Legenda aurea i el Recull d'eximplis”, Miscel-lània Joan Bastardas/4, vol. XXI, pp. 37-48. Barcelona: Publicaciones de l'Abadia de Montserrat.

JANSEN, K. L. (2001): The making of the Magdalen: preaching and popular devotion in the later Middle Ages. Princeton: Princeton University Press.

MAGGIONI, G. P. (2006): "Parole taciute, parole ritrovate. I racconti agiografici di Giovanni da Mailly, Bartolomeo da Trento e Iacopo da Varazze". Hagiographica 10: 183-200.

MyCOFF, D. (1989), The Life of Saint Mary Magdalene and of her Sister Saint Martha. A Medieval biography. Kalamazoo.

Pinto-MathiEu, E. (1997): Marie-Madeleine dans la littérature du Moyen-Age. Paris.

- Eadem (1998): "Trois vies de pécheresses repenties: les saintes Marie 1'Égyptienne, Marie Madeleine et Thaï". Revue des sciences humaines 251: 89-109. REAMES, S. L. (1985): The Legenda aurea: a reexamination of its paradoxical history, Madison.

SAXER, V. (1959): Le culte de Marie Madeleine en occident: des origines à la fin du Moyen Age, 2 vols. Auxerre.

- Idem (1998): "Philippe Cabassole et son Libellus Hystorialis Marie Beatissime Magdalene. Préliminaires à une édition du Libellus", en L'état angevin. Pouvoir, culture et société entre XIIle et XIVe siècle. Actes du Colloque international, Rome- Naples, 7-11 novembre 1995, pp. 193-204. Roma: Ecole Française de Rome-Istituto Storico Italiano per il Medio Evo.

VORAGINE, Iacobvs de (1998): Legenda aurea, edizione critica a cura di G. P. Maggioni, 2 vols. Firenze: Edizione del Galluzo.

VORAGINE, Jacques de (2004): La Légende dorée, introduction par A. Boureau; texte traduit, présenté et annoté par A. Boureau et alii. Gallimard: Éditions Gallimard. WALSH, J. K. - THOMPSON, B. B. (1986), The Myth of the Magdalen in Early Spanish Literature. Nueva York. 